\title{
OS FLUIDOS DE PERFURAÇÃO USADOS NA INDÚSTRIA DA ÁGUA SUBTERRÂNEA E SUA INFLUÊNCIA SOBRE OS PERFIS GEOFÍSICOS DE PRINCÍPIO ELÉTRICO
}

\author{
Geraldo Girão Nery ${ }^{1}$ e Renato Macari ${ }^{1}$
}

Recebido em 21/06/2004, aceito em 16/02/2005

\begin{abstract}
RESUMO Os fluidos de perfuração não controlam apenas as condições operacionais de perfuração. Também influenciam nas leituras dos perfis geofísicos dependentes da propagação do campo elétrico. Nos poços perfurados para explotação de água, a maioria dos fluidos é confeccionada a partir de materiais bentoníticos e poliméricos. Experiência de um fabricante deste último produto mostrou diferença significativa na resistividade aparente de camadas permeáveis em dois poços vizinhos - um perfurado com bentonita e o outro com polímero. Atribuíram tal comportamento apenas ao material sólido componente do fluido usado.O presente trabalho mostra que tal conclusão não corresponde à realidade. Dados coletados por seus autores sinalizam que as curvas elétricas convencionais (normais e laterais) são muito mais influenciadas pela máxima profundidade radial atingida pelo filtrado do fluido de perfuração (invasão) do que pelo tipo de material sólido nele usado. Fluidos poliméricos formam finos filmes impermeabilizantes nas paredes dos furos e apresentam pequenos diâmetros de invasão. Por outro lado, os fluidos bentoníticos formam espessos rebocos impermeabilizantes e invadem profundamente, influenciando de tal sorte as curvas elétricas fazendo com que elas registrem a resistividade da zona lavada/invadida e não a verdadeira, parâmetro necessário para a quantificação dos sais dissolvidos totais.
\end{abstract}

Palavras - chave: perfilagem geofísica, curvas elétricas normais, fluido de perfuração

\begin{abstract}
Drilling fluids not only control the well and improve drilling operations, they also affect the interpretation of geophysical well logs which depend on the propagation of electrical field. In water wells, the drilling muds are mostly made up of argillaceous or polymeric materials. In an experiment, logging two wells ten feet apart, one drilled with a polymeric mud and the other with a bentonitic mud, a manufacturer of drilling fluids demonstrated that the same permeable beds showed a significant difference in resistivity, and reached the conclusion that electrical logs are affected by the type of materials composing the drilling fluid. This paper shows this conclusion to be erroneous. A large number of data gathered by HYDROLOG clearly shows that resistivity differences between electrical curves are mostly function of the diameter of invasion and not of the type of material used in the drilling fluid. Polymeric fluids form a thin filmcake associated with a shallow invasion. On the other hand, bentonitic fluids create a thick mudcake associated with a deep invasion, and the shallow and deep electrical penetration measurements usually record the same resistivity, that of the flushed/invaded zone.
\end{abstract}

Keywords: geophysical well logs, electrical curves, drilling fluid

\section{INTRODUÇÃO}

Os fluidos de perfuração tiveram suas tecnologias desenvolvidas e ampliadas à proporção em que as sondagens rotativas e rotopneumáticas atingiam grandes profundidades e necessidades de controles paramétricos cada vez mais rígidos.

No início, eles eram constituídos de águas de rios, lagoas, mangues etc., com adição de algum tipo de argila e/ou incorporação de partículas resultantes do próprio ato de perfurar. Posteriormente, produtos naturais ou sintéticos foram acrescentados para que cada novo problema operacional correspondesse a uma solução adequada. Todavia, nem todos os produtos utilizados pela indústria do petróleo são adequados à indústria da água, dada a possibilidade de ocorrência de subprodutos decomposicionais que possam contaminar os aqüíferos secionados e/ou o meio ambiente.

Contudo, não se deve imaginar que tais fluidos sirvam apenas como um meio para atingir-se, com rapidez e eficiência, a profundidade final do furo. Deve-se levar, também, em consideração, que dentre as suas mais diversas propriedades algumas delas interessam mais de perto à avaliação exploratória de um poço, principalmente no que diz respeito aos perfis geofísicos de princípios físicos dependentes da propagação do campo elétrico (perfis elétricos convencionais tais como, normal curta, longa e lateral, respectivamente, RSN ou R16, RLN ou R64 e RLAT ou R18'8”, onde o R inicial sinaliza o tipo de sistema usado na medição). A necessidade de um contato galvânico entre os eletrodos dos perfis citados, é suprida pela presença dos sólidos coloidais orgânicos e inorgânicos (argilas, polímeros) e eletrólitos, provenientes de sais presentes na água de preparação e/ou introduzidos e incorporados aos fluidos por contaminações durante as sondagens.

A avaliação exploratória de um poço é iniciada com a primeira amostra de calha coletada e finalizada com os testes de produção, após uma série de procedimentos intermediários, tais como a perfilagem geofísica que registra as características petrofísicas tipo litologia, resistividade, argilosidade, porosidade, retenção específica, teor de sais dissolvidos totais etc..

${ }^{1}$ HYDROLOG Serviços de Perfilagens Ltda (hydrolog.ggn@uol.com.br), (hydrolog@uol.com.br) 
Algumas dessas propriedades resultam diretamente da leitura dos perfis, enquanto que outras necessitam do suporte laboratorial (macro e microscópico) das amostras de calha e/ou testemunhos, no que se convencionou chamar de correlação rocha x perfil. Além do mais, os perfis geofísicos também são usados para comparar padrões de curvas entre poços, visando mapeamentos de estruturas e/ou extensão areal de camadas permoporosas.

Portanto, no que se refere aos procedimentos essenciais para uma perfeita avaliação, de modo a proporcionar um meio físico realista para as operações de perfilagens, é essencial que se mantenha o fluido de perfuração dentro dos parâmetros estabelecidos para cada projeto específico, controlando-se: (1) a reologia necessária para o transporte do material triturado pela broca até a superfície para análise litológica, (2) os processos de filtração (visando minimizar a invasão radial das camadas permeáveis pelos sólidos e pela fase contínua do fluido) e da espessura do reboco (visando furos calibrados), (3) a hidratação de argilas expansivas presentes e, (4) as pressões de sub-superfície, por meio da densidade adequada à estabilidade do furo.

\section{MATERIAIS USADOS NOS FLUIDOS DE PERFURAÇÃO}

Os principais produtos usados na perfuração de poços para água são as argilas esmectíticas beneficiadas e polímeros naturais ou sintéticos.

Argilas - caracterizam-se pela predominância de partículas de tamanho menor que 0,004 mm com proporções diferenciadas de argilominerais e outros minerais. Por outro lado, os folhelhos, eventualmente incorporados aos fluidos de perfuração, são constituídos de pelos menos $60 \%$ de argilominerais (YAALON, 1962).

Os argilominerais esmectita (montmorilonita), atapulgita, ilita e caolinita podem ser usados em fluidos de perfuração. Porém, estes três últimos, além da esmectita policatiônica, não apresentam as mesmas propriedades da esmectita sódica (montmorilonita), no aspecto referente à geração de viscosidade, controle de filtrado e reboco e, principalmente, em atuar como agente tixotrópico. Desta forma, a montmorilonita é beneficiada industrialmente e denominada bentonita, constituindo-se no principal insumo de origem mineral utilizado em fluidos de perfuração para poços de água (PEREIRA, 2001).

Quando secos, os argilominerais apresentam cargas elétricas nas superfícies de suas micro- placas constituintes, as quais governam suas atividades eletroquímicas, conferindo-lhes características de atração e repulsão por moléculas eletricamente não balanceadas ou íons. Quando em contato com a água as cargas periféricas adsorvem as moléculas bipolares de água (hidratam-se) e, principalmente cátions do meio aquoso, difundem-se em um processo denominado de troca de cátions, formando um meio condutor que favorece o contato galvânico dos eletrodos dos perfis elétricos convencionais com as camadas adjacentes.

Os fluidos bentoníticos, chamados de alto teor de sólidos tem forte tendência a flocular devido à incorporação de sólidos durante a sondagem, na dependência do $\mathrm{pH}$ e na possibilidade de contaminação por $\mathrm{Ca}$ e $\mathrm{Mg}$. Com teores de sólidos superiores a $5 \%$, em termos de peso, advindos da incorporação e contaminações acima de $80 \mathrm{ppm}$ de $\mathrm{Ca}$ e $\mathrm{Mg}$, a floculação pode ocorrer em graus diversos, com a separação em duas fases, elevando substancialmente o processo de filtração e a espessura do reboco. Durante a floculação o arranjo das plaquetas de argila toma a forma de um castelo de cartas, favorecendo a livre circulação de água. O reboco também é muito mais permeável (PEREIRA, 2001).

GIRÃO NERY (1989), usando fluidos à base de bentonita e folhelhos naturais triturados da formação São Sebastião, demonstrou que seus efluentes (filtrados) tanto podem reter como liberar sais, na dependência da concentração da água usada na confecção dos mesmos. Quanto mais salina a água do fluido maior a retenção de sais pelos argilominerais presentes. Quanto mais diluída, maior a liberação de sais. Esta liberação ou retenção de sais estaria diretamente relacionada à filtração osmótica que se estabelece entre as diferentes concentrações dos macros e microporos entre as plaquetas dos argilominerais. O equilíbrio entre a retenção e a liberação indica o teor da salinidade das águas adsorvidas aos argilominerais, parâmetro exigido nas interpretações avançadas dos perfis geofísicos da indústria do petróleo.

Polímeros - são moléculas alongadas, constituídas de cadeias de carbonos com unidades menores (monômeros), idênticas e repetidas. Podem ter origem natural, natural modificada ou sintética. Quando naturais, tipo amido ou celulose, são insolúveis e formam soluções não iônicas e, portanto, não conduzem a corrente elétrica. Os polímeros naturais podem ser industrialmente modificados para polieletrólitos que se dissolvem em água 
formando poliíons e íons neutralizados por cargas opostas. A efetividade dos polímeros modificados depende de sua pureza, comprimento de sua cadeia (peso molecular), grau e uniformidade de substituição, a qual deve expor o maior número de cargas elétricas possíveis para capturar o máximo de cargas livres distribuídas no meio em que estão solubilizados. Estas propriedades também se atribuem aos polímeros sintéticos, que ainda podem ter peso molecular e quantidade de cargas dezenas de vezes maiores que os naturais modificados.

Pelo fato de os polímeros naturais modificados ou sintéticos possuírem cargas elétricas periféricas, quando são imersos em água e solubilizados, formam uma estrutura de rede microscópica capaz de gerar a característica de viscosidade e ainda serem condutores elétricos, isto é, com características similares às argilas. Os fluidos poliméricos, com teores de sólidos menores que $5 \%$, inibem o processo de floculação pela minimização do problema da circulação de água e do reboco, tal como observado nos fluidos bentoníticos. Estudos demonstram que em fluidos aditivados ocorre a floculação em algumas situações (teor > 5\% e pH $>7,8$ ), mas o estado é de floculado-gel. Neste estado o fluido não apresenta textura homogênea e, mesmo assim, a quantidade de água livre é muito menor (PEREIRA, 2001).

\section{O MEIO AMBIENTE DE FERRAMENTA DE PERFILAGEM}

UMA

Durante a perfuração de um poço tubular o diferencial de pressão entre o fluido $(\mathrm{Pm})$ e a formação ou camada (Pf), desde que Pm>Pf, é o responsável por pressionar o fluido contra a superfície permoporosa das paredes das camadas perfuradas. Este diferencial origina um processo de filtração, denominado de invasão, constando de duas etapas distintas: (1) a invasão do filtrado (parte líquida do fluido de perfuração) juntamente com alguns sólidos, na porção inicial do envoltório, sendo a fase contínua do fluido a que mais avança e, (2) a retenção das partículas sólidas que se depositam na parede do furo formando um reboco, nos fluidos com bentonita, ou um filme, nos fluidos com polímero (PEREIRA, 2001).

Radialmente, a invasão origina várias zonas fluidas (Figura 1), circunvizinhas ao furo, as quais devem ser levadas em consideração na avaliação de todo e qualquer tipo de perfil geofísico. Na primeira destas zonas, a lavada, o filtrado invasor predomina devido à expulsão quase total do fluido pré-existente (empurrado para mais internamente da camada), misturado com o fluido residual adsorvido aos grãos (retenção específica em hidrogeologia e saturação de água irredutível no petróleo). Segue-se uma zona invadida, transitória e de espessura variável, onde ocorre uma difusão entre o filtrado invasor e o fluido intersticial original. A última e a mais profunda, a zona virgem ou verdadeira, encontrase livre da influência do filtrado invasor contendo somente o fluido original. Sendo o fluido saturante monofásico (água intersticial), a resistividades desta zona é convencionada de Ro. Sendo o fluido saturante trifásico (água, gás e/ou petróleo), a resistividade desta zona é convencionada de Rt. Portanto, a zona virgem é a desejável para a investigação dos perfis de resistividade.

Denomina-se de diâmetro de invasão (Di) o diâmetro relativo à máxima penetração do filtrado em uma camada. O diâmetro de invasão está relacionado de modo complexo com fatores intrínsecos às camadas, tais como a permeabilidade e a porosidade e, extrínsecos, como o tempo de perfuração (portanto, maior número de manobras e conseqüentes raspagens do reboco) e a diferença de pressão entre o fluido de perfuração e a da camada em si. Experiências têm demonstrado que o reboco produzido pelas lamas bentoníticas, ou o filme das lamas poliméricas diferem entre si no que diz respeito ao formato, tamanho e capacidade de hidratação das partículas envolvidas no processo. Os rebocos das lamas bentoníticas são mais espessos (da ordem de fração de polegadas) que os filmes poliméricos. Quanto mais espesso o reboco, maior a filtração, maior a perda de água para as camadas, maior o diâmetro de invasão.

Uma propriedade altamente desejável nos fluido de perfuração é a de impermeabilização das paredes dos furos (pela deposição do reboco ou filme) e a menor liberação de filtrado para as camadas, de modo a evitar uma invasão muito profunda, o que irá prejudicar não somente a perfilagem em si, mas também favorecer danos nas formações permoporosas, prejudicando a recuperação posterior do fluido a explorar (água ou hidrocarbonetos).

De acordo com a Lei Experimental de ARCHIE (1942), a resistividade de uma rocha isenta de elementos condutivos outros que não a água intersticial, pode ser determinada por meio da seguinte relação:

$$
\mathrm{Ro}=\frac{\mathrm{a} \cdot \mathrm{Rw}}{\phi^{\mathrm{m}}}
$$


onde, $\phi$ é a porosidade, Ro é a resistividade da zona virgem, totalmente saturada com água intersticial (i.é, sem nenhuma influência do filtrado), e Rw é a resistividade da água original que satura os poros da camada. Os coeficientes a e m são parâmetros influenciados pela geometria porosa da rocha. Em outras palavras, a resistividade de uma rocha é diretamente proporcional à qualidade (Rw) e inversamente proporcional à quantidade $(\phi)$ da água contida em seus poros.

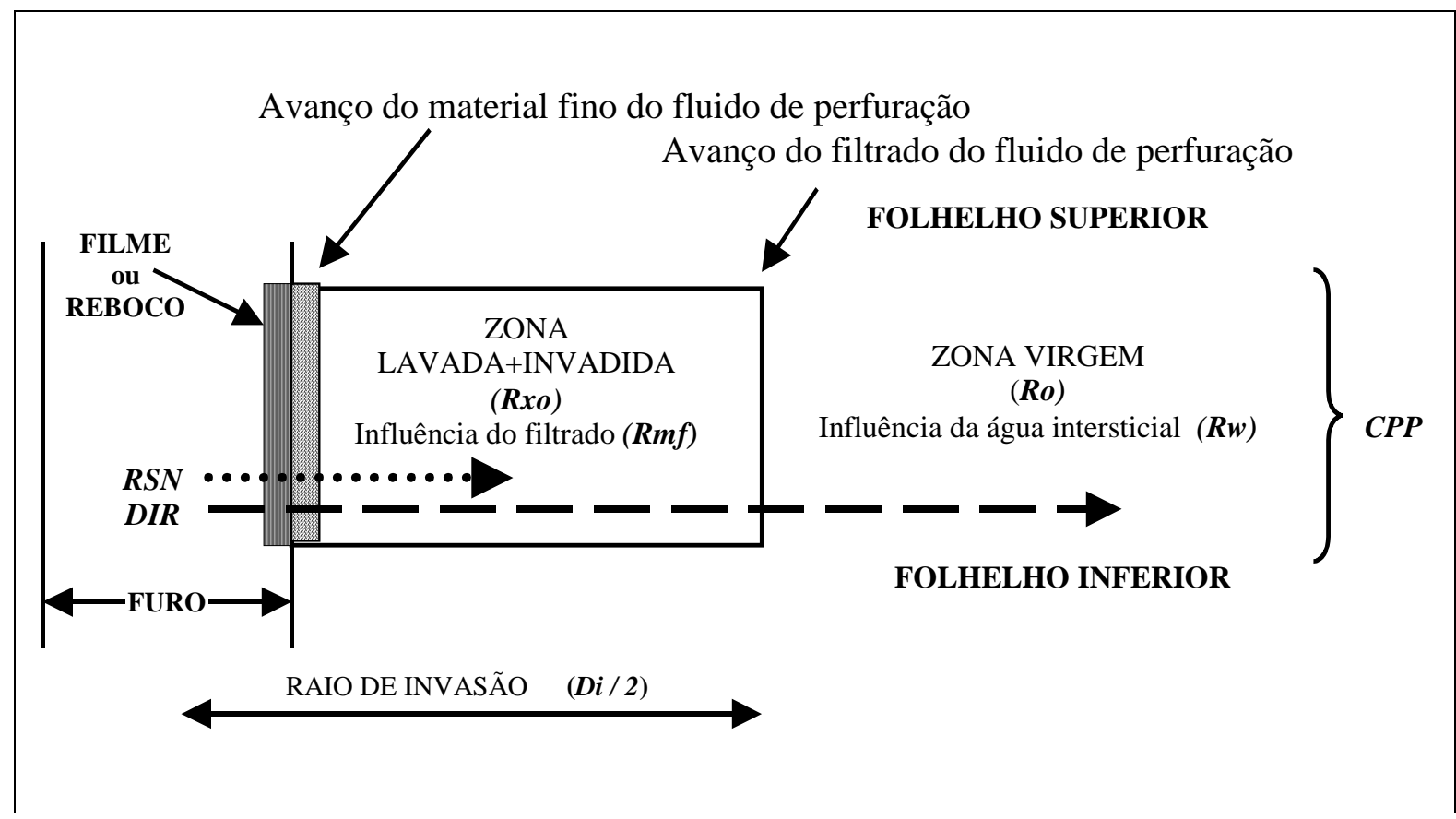

Figura 1 - Ilustração mostrando a relação entre o Raio de Invasão (Di/2) em uma camada permoporosa (CPP) e a profundidade radial de investigação das curvas RSN (seta pontilhada) e DIR (seta tracejada). O contato entre as zonas lavada/invadida (de resistividade Rxo) e a zona virgem (de resistividade Ro) não é abrupto, conforme a figura parece demonstrar, mas sim, transicional. Rxo é mais influenciada pela presença do filtrado (de resistividade $=\mathrm{Rmf}$ ) enquanto que Ro, pela água intersticial (de resistividade $=\mathrm{Rw}$ ). Rxo e Ro serão diferentes sempre que Rmf for diferente de Rw. Em camadas com invasão nula ou impermeável ou ainda quando $\mathrm{Rmf}=\mathrm{Rw}$, Rxo tenderá a Ro.

Segundo LIMA et al. (2001), o fenômeno da condução elétrica em um meio granular poroso é ocasionado, primariamente, pelo transporte de íons dissolvidos em seus eletrólitos porosos e, também, pelo deslocamento e difusão dos cátions adsorvidos nas paredes de seus poros. Em condições úmidas tais cátions adsorvidos desenvolvem uma nuvem ou uma dupla camada nas proximidades das interfaces sólida-líquida. Quando as águas intersticiais são salinas, a contribuição devida à dupla camada torna-se constante. Para tais situações equações semiempíricas foram desenvolvidas e aplicadas com sucesso WAXMAN; SMITS (1968), CLAVIER et al. (1984) e LIMA; DALCIN (1995). Nas condições de aqüíferos com água doce a lei de ARCHIE (1942) falha em sua aplicação (ALGER; HARRISON, 1989), necessitando de uma correção em função da resistividade das argilas (RSH) sobre e sotopostas à camada em estudo e seu volume (VSH) determinado pela curva dos Raios Gama.

Como ARCHIE (1942) trabalhou com rochas sabidamente granulares e isentas de argila, e não tenha mencionado o tipo de porosidade de suas amostras (total, efetiva, fissural etc), presume-se que ela seja referente às águas interporosas interligadas, no caso a porosidade efetiva (LIMA et al., 2005).

\section{O COMPORTAMENTO ELÉTRICO DOS FLUIDOS DE PERFURAÇÃO}

A qualidade dos perfis elétricos convencionais (RSN, RLN e RLAT) fica bastante comprometida quando se usa água relativamente salinizada (condutiva) nos fluidos de perfuração, 
pela dificuldade natural que a corrente elétrica terá para penetrar nas camadas mais resistivas. Logo após a saída do eletrodo emissor, as linhas de corrente tendem a ficar confinadas dentro da coluna de fluido, pouco ou nada investigando a zona lavada/invadida e muito menos a zona virgem. A qualidade dos referidos perfis também fica comprometida quando se usa água pouco salinizada (resistiva) devido a coluna isolante, que envolve o eletrodo emissor, não permitir a penetração da corrente nas camadas.

Para uma correta avaliação, usando-se os perfis elétricos convencionais, o fluido de perfuração não deve ser nem totalmente isolante nem condutivo para (1) favorecer o contato galvânico entre os eletrodos e as camadas, (2) possibilitar as linhas de corrente sairem radialmente dos eletrodos sem distorções e, (3) registrar valores realistas de resistividades.

Deve-se adiantar que ambas as situações (fluidos diluídos ou concentrados) tornam-se ainda mais críticas quando os furos têm diâmetros da ordem de 4 ou mais vezes o diâmetro dos sensores das ferramentas usadas (SCHLUMBERGER,1989).

É importante frisar que os perfis de princípios elétricos puros, ou convencionais, desde há muito não são usados pela indústria do petróleo substituídos que foram pelos perfis do tipo Indução 6FF40. Simplificadamente, este perfil consta de três pares de bobinas, onde uma bobina transmissora principal dista 40 polegadas de uma receptora principal. A transmissora é ativada por uma corrente alternada de freqüência constante, emitindo um campo magnético primário de formato de um toróide (sólido gerado pela rotação de uma superfície plana fechada em torno de um eixo que não lhe seja secante), em direção às camadas circunvizinhas. Por sua vez, este campo interage com as camadas dando origem a um campo secundário diretamente proporcional à condutividade das mesmas. O Indução registra a força eletromotriz que atua sobre a bobina receptora, transformando-a em valores de resistividade.

Os campos magnéticos, quer primário quer secundário, não são distorsivos como o campo elétrico, mesmo nas condições adversas de até 30.000 ppm de salinidade do fluido de perfuração (SCHLUMBERGER, 1989), incomum na indústria da água. Quanto menos condutivo o meio que envolve as bobinas (fluido a base de água doce ou óleo), mais profunda será a investigação da curva de Indução dentro da zona virgem, isto é, ela tenderá registrar Ro e não Rxo. Como na indústria da água o fluido de perfuração tem por base as águas superficiais, este deveria ser o perfil usado para eliminar problemas desta natureza.

\section{OBJETIVO DO TRABALHO}

A necessidade básica da perfilagem geofísica, para a indústria da água, está na definição das camadas permoporosas (para tanto são usadas as curvas de Raios Gama e do Potencial Espontâneo) e no cálculo da resistividade da água intersticial das camadas (Rw).

A maior ou menor diferença, visual ou numérica, que possa ser observada entre duas curvas resistivas, uma rasa como a RSN e uma medianamente profunda como a RLN, ou mesmo uma bem mais profunda como a DIR, não implica necessariamente em uma maior ou menor permeabilidade da camada, mas sim em uma relação complexa entre o diâmetro de invasão e o poder de penetração de cada uma das referidas curvas (Figura 1). Assim, um bom fluido de perfuração, para poder apresentar isenção na avaliação das camadas, deve ter o seu volume de filtrado, devida e constantemente controlado. Caso contrário, os perfis de resistividade estarão mapeando Rxo e não Ro.

Por analogia, a lei de ARCHIE (1942) pode ser usada para definir, também, a resistividade da zona lavada/invadida (Rxo), isto é:

$$
\mathrm{Rxo}=\frac{\mathrm{a} \cdot \mathrm{Rmf}}{\phi^{\mathrm{m}}}
$$

Em outras palavras, Rxo é função da resistividade do filtrado invasor (Rmf) enquanto que Ro é função da resistividade da água intersticial (Rw). Por sua vez, Rw depende do teor de sais dissolvidos totais (SDT), segundo relações hiperbólicas definidas por GIRÃO NERY (1996, 2000):

$$
\mathrm{SDT}=\frac{\mathrm{b}}{\mathrm{Rw}^{\mathrm{C}}}, \quad \text { onde } \quad \mathrm{Rw}=\frac{\phi^{\mathrm{m}} \cdot \mathrm{Ro}}{\mathrm{a}}
$$

Os dados obtidos a partir dos perfis geofísicos, desde que bem controlados qualitativamente: resistividade verdadeira da rocha (Ro) e a porosidade $(\phi)$, tornam possível o cálculo de Rw e, por conseqüência, do SDT. Os parâmetros $a$ e $m$ devem, preferentemente, resultar de estudos laboratoriais de correlação rocha $x$ perfil, enquanto que a porosidade $(\phi)$ deve ser corrigida pelo efeito da argilosidade, definida com o uso dos perfis de Raios Gama, Potencial Espontâneo e outros. 
Ora, se uma camada está profundamente invadida, as resistividades lidas pelas curvas elétricas convencionais (RSN e RLN) sofrerão influência maior do filtrado invasor (Rmf) do que da água intersticial (Rw), expulsa pela invasão; isto é, elas tenderão a ler Rxo. Portanto, não é muito aconselhável o uso indiscriminado de tais curvas nos cálculos quantitativos, uma vez que sendo distorsivas, na presença de fluidos de perfuração isolantes e/ou condutivos, a sua penetração radial de investigação estará comprometida. Por outro lado, a curva de indução profunda 6FF40 (DIR - "Deep Induction
Resistivity"), tenderá registrar a Ro, conforme pode ser observado na figura 1.

STOTT; SMITH (1974), afirmaram que as curvas elétricas são afetadas pela diferença de resistividade entre os fluidos do furo e do aqüífero. Ilustraram (Figura 2) tal afirmativa usando duas curvas elétricas (que, devido à data do trabalho e por falta de maiores informações, acredita-se ser de arranjo normal com uma separação não convencional de 0,25 pés ou 7,6 $\mathrm{cm}$ entre eletrodos), realizadas em dois furos separados por 10 pés $(3 \mathrm{~m})$.

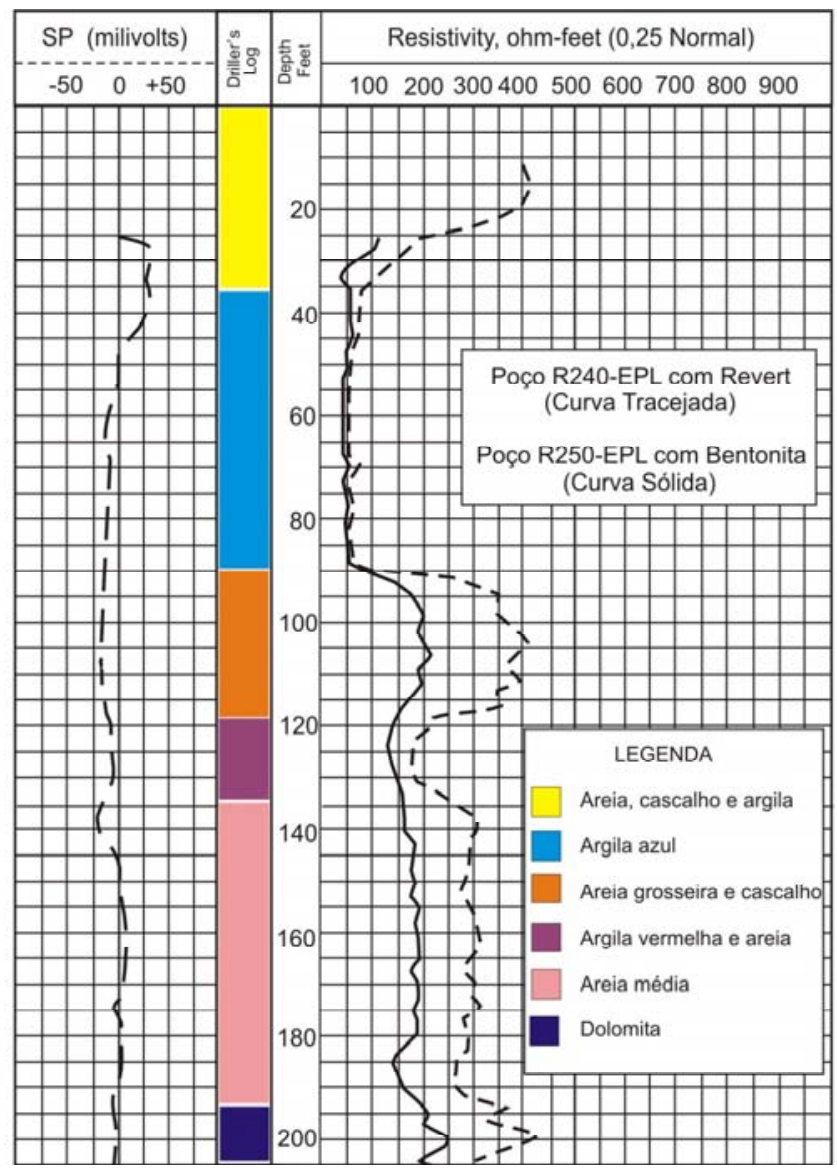

Figura 2 - Curvas de resistividade registradas em dois poços vizinhos, distantes 10 pés, perfurados com fluidos distintos, mostrando diferenças marcantes defronte a camadas permeáveis, atribuídas exclusivamente ao tipo de fluido. Adaptado de STOTT; SMITH (1974)

Observa-se na figura 2, que as curvas de resistividade registradas na camada de argila azul, superior e impermeável, entre 36 e 90 pés de profundidade, apresentam coerente e igualmente cerca de 60 ohm.pé (a unidade convencionada em perfilagem é o ohm.m). Na camada de areia grosseira e cascalho, alaranjada e intermediária, entre 90 e 120 pés, a resistividade lida no furo com bentonita (curva cheia) é da ordem de 200 ohm.pé, enquanto que a do furo com polímero (curva tracejada) registra o dobro daquele valor. Igual comportamento pode ser observado na areia média rosa inferior, entre 137 e 190 pés, com 200 e 300 ohm.pé, respectivamente. Os autores justificaram tais fatos dizendo que "o uso da bentonita faz com que a resistividade do fluido de perfuração seja, usualmente, menor do que a água doce do 
aqüífero. Por outro lado, fluidos orgânicos exibem maiores resistividades que os bentoníticos”.

O presente trabalho teve como objetivo verificar se a presença de polímeros nos fluidos de perfuração poderia ocasionar comportamento elétrico diferenciado, em relação aos fluidos de perfuração bentoníticos sabidamente condutores.

Diversos tipos de polímeros estão à disposição dos perfuradores, quer para a perfuração de poços para a água, quer para o petróleo. Para evitar implicações comerciais usou-se o termo genérico polímero.

\section{METODOLOGIA USADA}

As empresas prestadoras de serviço de perfilagem preenchem um cabeçalho que identificam cada furo por seus dados de natureza geográfica, topográfica, da perfuração em si e do fluido de perfuração. Alguns desses dados têm utilidade nos cálculos interpretativos, entre eles a resistividade do filtrado (Rmf) medida à temperatura ambiente. Ressalve-se que todos os dados contidos nos cabeçalhos, principalmente aqueles relacionados às características do fluido de perfuração (tipo, densidade, viscosidade etc.), são fornecidos pelos perfuradores ou seus representantes no canteiro da obra. As companhias de perfilagem não têm como atestar ou contestar suas veracidades, restando-lhes apenas medir a resistividade das amostras entregues e registrá-las como tal.

Analisou-se neste trabalho, a partir do banco de dados da HYDROLOG, um total de 355 medidas de Rmf, sendo 162 de amostras provenientes de fluidos de perfuração ditos como poliméricos e de 193 ditos bentoníticos. As amostras dos filtrados foram medidas com um resistivímetro de fabricação Schlumberger, modelo EMT, com quatro eletrodos (A-M-N-B), número de série 1393, com precisão nominal absoluta de 0,001 Ohm.m e relativa variando entre 0,5 e $1 \%$ no intervalo analisado. Para fins de comparação, todas resistividades medidas foram convertidas para a temperatura padrão de $25{ }^{\circ} \mathrm{C}$.

A figura 3 ilustra graficamente os resultados das medidas das resistividades dos filtrados e a tabela 1 um resumo estatístico. Os fluidos bentoníticos apresentaram valores máximos um pouco menores que os poliméricos. Demais resultados mostraram diferenças mínimas sem afastamentos significativos. As resistividades dos filtrados gerados por ambos os tipos de fluidos de perfuração tiveram um comportamento elétrico similar, independentes do tipo de material presente e sim da resistividade da água usada na sua confecção. Como seria de esperar, quanto mais diluída a água usada, maior o valor de Rmf, quanto mais concentrada ou salinizada, menor o Rmf.

\section{CORRELAÇÃO ENTRE POÇOS DISTANTES}

Com base no comportamento das resistividades das 355 amostras de filtrados, escolheu-se quatro poços localizados na região metropolitana de São Paulo, capital, para fins de constatação dos resultados obtidos. As curvas de resistividade apresentam razoável a ótima correlação, enquanto que os Raios Gama foram prejudicados pela litologia predominante de diamictitos e conglomerados polimíticos imaturos, dispersos em matriz lamítica a arenosa. Localmente, ocorrem corpos arenosos, mal selecionados, de pequena espessura em meio a sedimentos sílticos argilosos.

Definiu-se, em cada poço, três intervalos (superior, médio e inferior) com base no aspecto das curvas de resistividade. O intervalo médio destaca-se pela predominância argilosa (ambas as curvas apresentam baixos valores), enquanto que os intervalos superior e inferior destacam-se pela predominância arenosa (altas resistividades). As figuras 4 e 5 e as tabelas 2 e 3 mostram os poços estudados identificados por seus respectivos Rmfs e tipos de fluido de perfuração. 


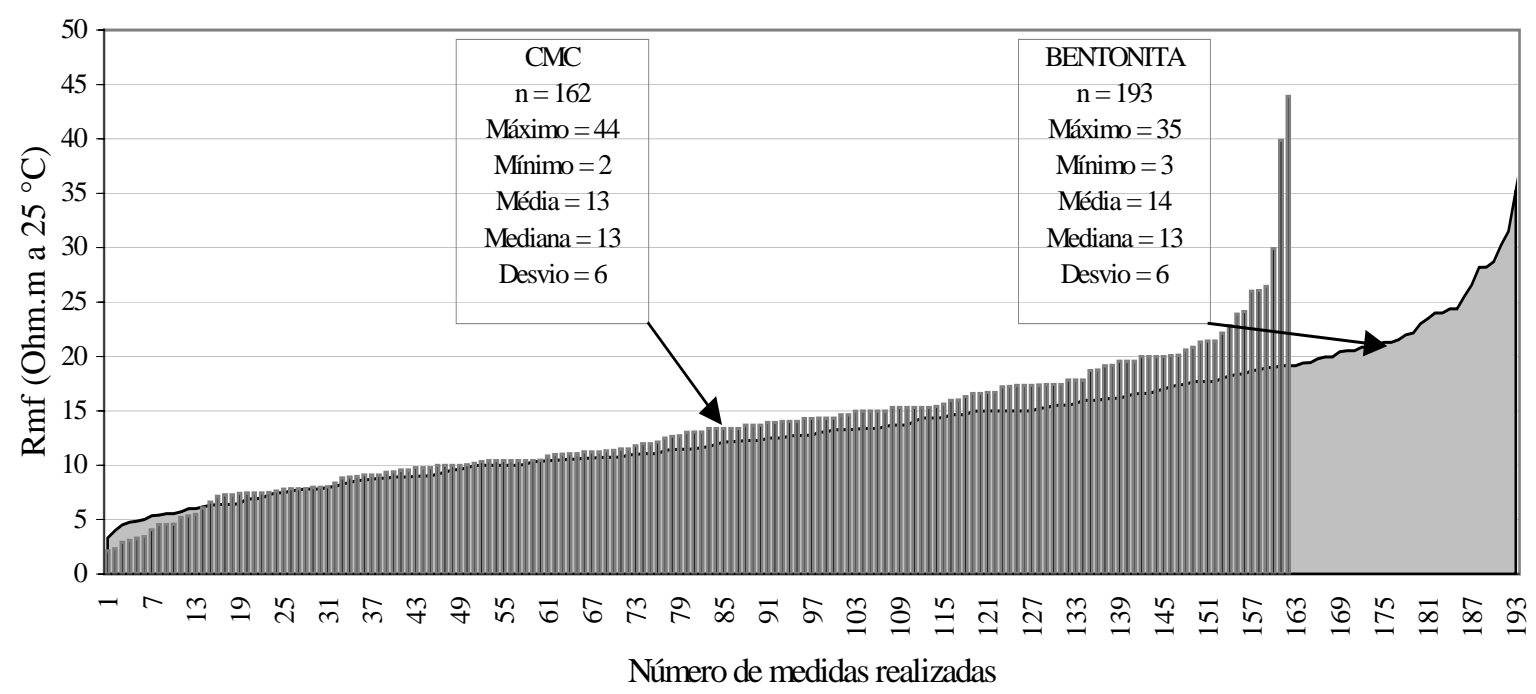

Figura 3 - Resultados das medidas das resistividades de filtrados (Rmf) em 162 amostras de fluidos de perfuração, relatados como poliméricos e 193 de fluidos relatados como bentoníticos. A esquerda da figura situam-se os fluidos condutivos e a direita, os resistivos. Os valores de Rmf mostram comportamentos similares, independentes do tipo material presente, mas sim da resistividade da água usada na confecção do fluido de perfuração.

Tabela 1 - Estatística dos resultados das leituras das 355 amostras de filtrados ( $R m f$ ) de fluidos de perfuração (banco de dados da HYDROLOG), mostrados na figura 3. Os valores em negrito estão expressos em ohm.m a $25^{\circ} \mathrm{C}$.

\begin{tabular}{l|c|c}
\hline \multicolumn{1}{c|}{ ESTATÍSTICA } & $\begin{array}{c}\text { FLUIDO DE PERFURAÇÃO } \\
\text { COM POLÍMERO }\end{array}$ & $\begin{array}{c}\text { FLUIDO DE PERFURAÇÃO } \\
\text { COM BENTONITA }\end{array}$ \\
\hline Medidas Realizadas & 162 & 193 \\
\hline Leituras Máximas & $\mathbf{4 4}$ & $\mathbf{3 5}$ \\
\hline Leituras Mínimas & $\mathbf{2}$ & $\mathbf{3}$ \\
\hline Leituras Médias & $\mathbf{1 3}$ & $\mathbf{1 4}$ \\
\hline Leituras Medianas & $\mathbf{1 3}$ & $\mathbf{1 3}$ \\
\hline Desvio Padrão & 6 & 6 \\
\hline
\end{tabular}

O poço 2, com polímero, apresenta valores medianos da DIR consistentemente mais altos que no poço 1 , com bentonita. Pelo fato de os fluidos com polímero proporcionarem invasões rasas, a DIR é muito mais influenciada pelo fluido original do aqüífero e não pelo filtrado invasor tendendo, portanto, a Ro. Mesmo que ambas as curvas sofram influência de Ro, todavia, como a DIR é o produto de uma ferramenta de princípio elétrico magnético não distorsivo, ela é numericamente mais confiável que a elétrica RSN, para uso nos cálculos de SDT. Por outro lado o poço 1, com bentonita, muito embora tenha um Rmf mais resistivo, apresenta consistentemente valores de DIR e RSN menores que no poço 2. Este fato sinaliza a maior condutividade dada pela bentonita, em comparação com o polímero, e justifica a possibilidade da tendência de ambas as curvas estarem lendo Rxo. Nestes casos, os valores calculados para SDT serão irreais.

Igual comportamento resistivo pode ser observado na figura 5 e tabela 3. Chama-se a atenção para os valores aproximados entre as resistividades dos filtrados dos poços 3 e 4 . 
Poço 1

Fluido de Perfuração = BENTONITA $\mathrm{Rmf}=13,4$ ohm.m a $25^{\circ} \mathrm{C}$
Poço 2

Fluido de Perfuração = POLÍMERO $\mathrm{Rmf}=9$ ohm.m a $25^{\circ} \mathrm{C}$

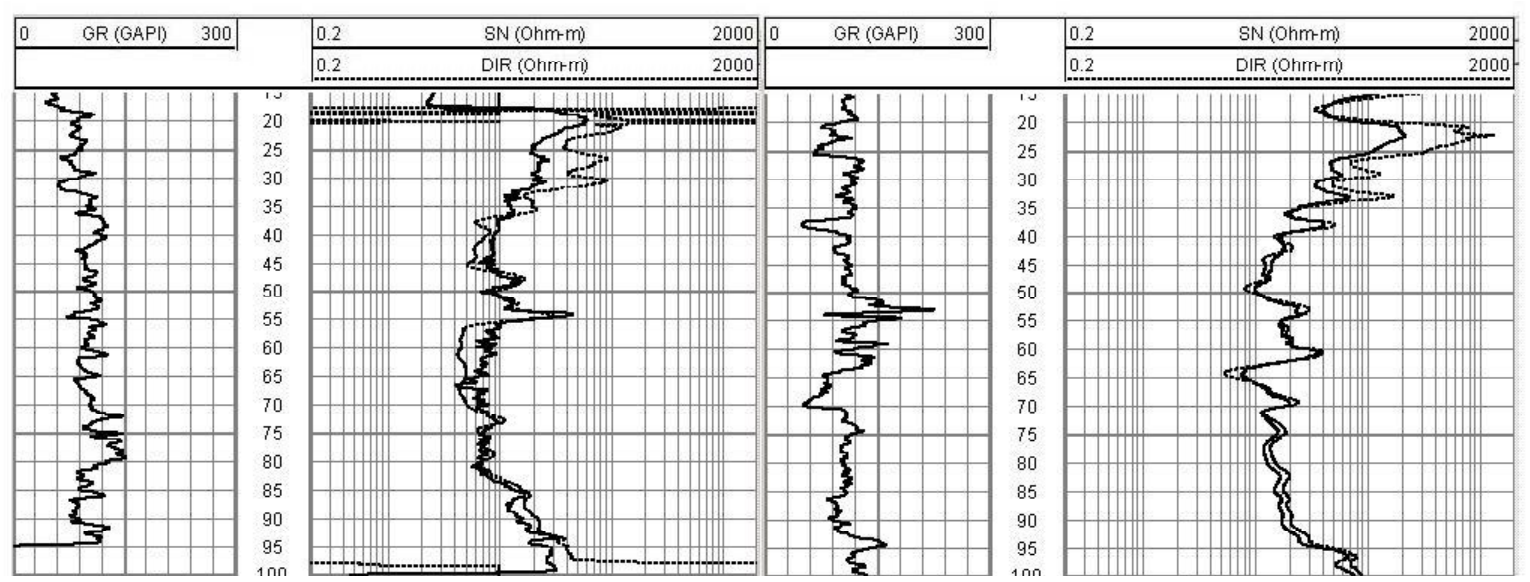

Figura 4 - Poço 1 distante $3 \mathrm{~km}$ do poço 2, ambos perfurados com fluidos distintos. As altas resistividades do poço 2 (à direita), com fluido de perfuração polimérico, resultam de uma invasão rasa e, portanto, com maior influência da zona virgem $(R o)$, muito embora seu Rmf seja mais condutivo. Os valores da DIR e RSN do poço 1 (à esquerda) são consistentemente inferiores ao do poço 2, demonstrando a maior influência da invasão e condutividade da bentonita.

Tabela 2 - Estatística das curvas mostradas na figura 4, correspondendo aos poços 1 e 2

\begin{tabular}{|c|c|c|c|c|c|}
\hline \multicolumn{3}{|c|}{$\begin{array}{c}\text { POÇO } 1 \\
\text { LAMA BENTONITA } \\
\text { Rmf }=13,4 \text { ohm.m a } 25^{\circ} \mathrm{C}\end{array}$} & \multicolumn{3}{|c|}{$\begin{array}{c}\text { POÇO } 2 \\
\text { LAMA POLÍMERO } \\
\text { Rmf }=9 \text { ohm.m a } 25^{\circ} \mathrm{C}\end{array}$} \\
\hline \multicolumn{3}{|c|}{ INTV. SUPERIOR = 20,5 - 56,5 m } & \multicolumn{3}{|c|}{ INTV. SUPERIOR = $15-63 \mathrm{~m}$} \\
\hline $\begin{array}{l}\text { Máximo } \\
\text { Mínimo } \\
\text { Média } \\
\text { Mediana }\end{array}$ & $\begin{array}{c}\text { DIR } \\
247,26 \\
5,10 \\
30,16 \\
16,46 \\
\end{array}$ & $\begin{array}{c}\mathrm{SN} \\
57,67 \\
6,72 \\
16,65 \\
12,87 \\
\end{array}$ & $\begin{array}{l}\text { Máximo } \\
\text { Mínimo } \\
\text { Média } \\
\text { Mediana }\end{array}$ & $\begin{array}{c}\text { DIR } \\
1.248,92 \\
81,18 \\
108,21 \\
29,66\end{array}$ & $\begin{array}{c}\mathrm{SN} \\
215,55 \\
10,03 \\
46,07 \\
25,3 \\
\end{array}$ \\
\hline \multicolumn{3}{|c|}{ INTV. MÉDIO = 56,6 - $71 \mathrm{~m}$} & \multicolumn{3}{|c|}{ INTV. MÉDIO = 63,1 - 94 m } \\
\hline $\begin{array}{l}\text { Máximo } \\
\text { Mínimo } \\
\text { Média } \\
\text { Mediana }\end{array}$ & $\begin{array}{l}\text { DIR } \\
5,90 \\
4,26 \\
4,75 \\
4,71 \\
\end{array}$ & $\begin{array}{c}\text { RSN } \\
10,18 \\
4,06 \\
7,20 \\
7,14 \\
\end{array}$ & $\begin{array}{l}\text { Máximo } \\
\text { Mínimo } \\
\text { Média } \\
\text { Mediana }\end{array}$ & $\begin{array}{c}\text { DIR } \\
30,7 \\
5,35 \\
17,2 \\
17,84 \\
\end{array}$ & $\begin{array}{c}\text { RSN } \\
215,55 \\
7,63 \\
33,89 \\
15,07 \\
\end{array}$ \\
\hline \multicolumn{3}{|c|}{ INTV. INFERIOR = 71,1 m - PF } & \multicolumn{3}{|c|}{ INTV. INFERIOR = 94,1 m - PF } \\
\hline $\begin{array}{l}\text { Máximo } \\
\text { Mínimo } \\
\text { Média } \\
\text { Mediana }\end{array}$ & $\begin{array}{c}\text { DIR } \\
12.458,68 \\
6,17 \\
127,66 \\
15,29\end{array}$ & $\begin{array}{c}\text { GR } \\
33,92 \\
5,72 \\
13,96 \\
11,99\end{array}$ & $\begin{array}{l}\text { Máximo } \\
\text { Mínimo } \\
\text { Média } \\
\text { Mediana }\end{array}$ & $\begin{array}{c}\text { DIR } \\
23.110,35 \\
29,51 \\
192,7 \\
45,86\end{array}$ & $\begin{array}{c}\mathrm{SN} \\
318,48 \\
24,94 \\
60,49 \\
39,68\end{array}$ \\
\hline
\end{tabular}


Poço 3

Fluido de Perfuração $=$ BENTONITA $\mathrm{Rmf}=12,8$ ohm.m a $25^{\circ} \mathrm{C}$
Poço 4

Fluido de Perfuração = BENTONITA $\mathrm{Rmf}=15,0$ ohm.m a $25^{\circ} \mathrm{C}$
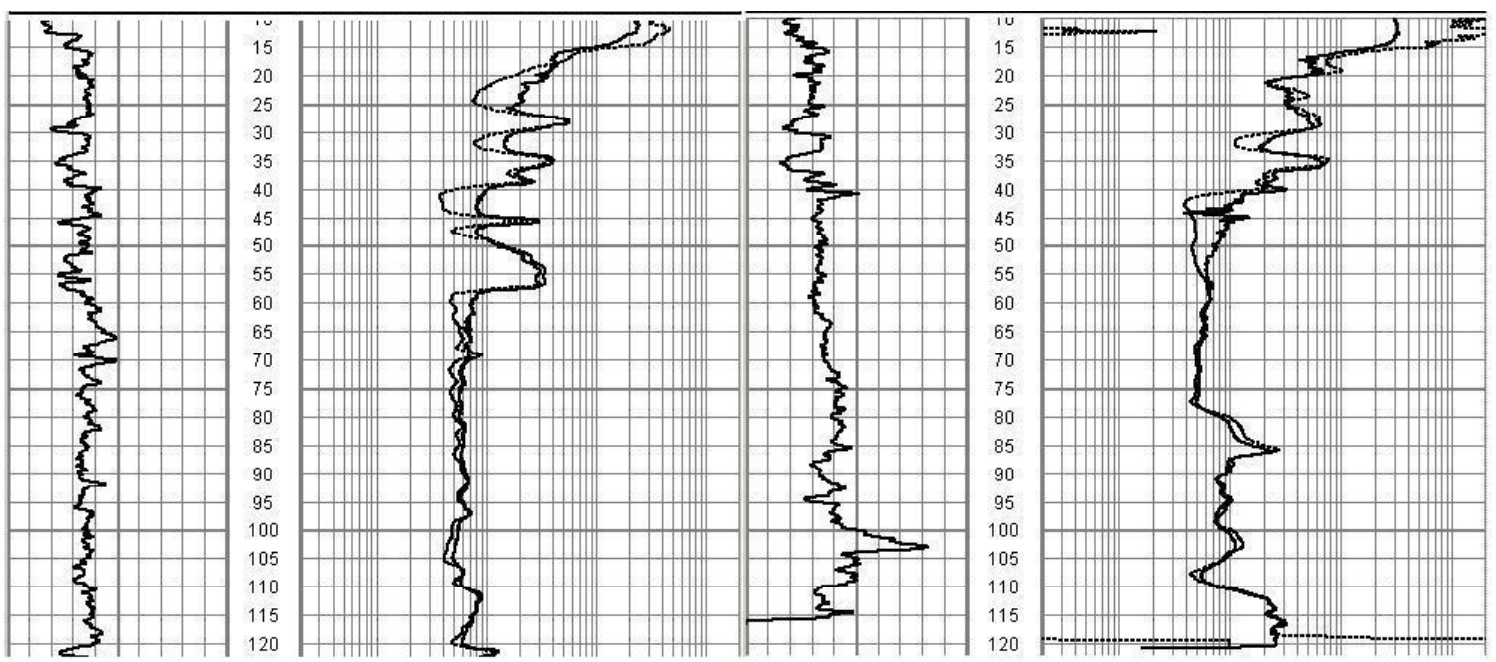

Figura 5 - Poço 3 distante 1,5 km do poço 4, ambos também perfurados com fluidos distintos. As altas resistividades do poço (4 à direita), com fluido de perfuração polimérico, resultam de uma invasão rasa e, portanto, com maior influência da zona virgem $(R o)$, muito embora ambos Rmf sejam aproximados. Os valores da DIR e RSN do poço 3 são consistentemente inferiores ao do poço 4, demonstrando a maior influência da invasão e condutividade da bentonita.

Tabela 3 - Estatística das curvas mostradas na figura 5, correspondendo aos poços 3 e 4 .

\begin{tabular}{|c|c|c|c|c|c|}
\hline \multicolumn{3}{|c|}{$\begin{array}{c}\text { POÇO } 1 \\
\text { LAMA BENTONITA } \\
\operatorname{Rmf}=13,4 \text { ohm.m a } 25^{\circ} \mathrm{C}\end{array}$} & \multicolumn{3}{|c|}{$\begin{array}{c}\text { POÇO } 2 \\
\text { LAMA POLÍMERO } \\
\text { Rmf }=9 \text { ohm.m a } 25^{\circ} \mathrm{C}\end{array}$} \\
\hline \multicolumn{3}{|c|}{ INTV. SUPERIOR = $10-58,1 \mathrm{~m}$} & \multicolumn{3}{|c|}{ INTV. SUPERIOR $=15-63 \mathrm{~m}$} \\
\hline $\begin{array}{l}\text { Máximo } \\
\text { Mínimo } \\
\text { Média } \\
\text { Mediana } \\
\end{array}$ & $\begin{array}{c}\text { DIR } \\
461,48 \\
3,74 \\
55,20 \\
18,44 \\
\end{array}$ & $\begin{array}{c}\mathrm{SN} \\
245,11 \\
4,87 \\
43,00 \\
23,39 \\
\end{array}$ & $\begin{array}{l}\text { Máximo } \\
\text { Mínimo } \\
\text { Média } \\
\text { Mediana } \\
\end{array}$ & $\begin{array}{c}\text { DIR } \\
10.236,89 \\
4,02 \\
380,89 \\
50,65 \\
\end{array}$ & $\begin{array}{c}\mathrm{SN} \\
332,98 \\
11,28 \\
93,65 \\
44,57 \\
\end{array}$ \\
\hline \multicolumn{3}{|c|}{ INTV. MÉDIO = 58,1 - 110,2 m } & \multicolumn{3}{|c|}{ INTV. MÉDIO = 42,4 - 80,2 m } \\
\hline $\begin{array}{l}\text { Máximo } \\
\text { Mínimo } \\
\text { Média } \\
\text { Mediana }\end{array}$ & $\begin{array}{l}\text { DIR } \\
7,21 \\
4,10 \\
5,46 \\
5,40 \\
\end{array}$ & $\begin{array}{l}\text { RSN } \\
9,62 \\
4,87 \\
6,29 \\
6,13 \\
\end{array}$ & $\begin{array}{l}\text { Máximo } \\
\text { Mínimo } \\
\text { Média } \\
\text { Mediana }\end{array}$ & $\begin{array}{c}\text { DIR } \\
9,86 \\
3,91 \\
5,30 \\
10,82 \\
\end{array}$ & $\begin{array}{c}\text { RSN } \\
14,77 \\
3,91 \\
6,61 \\
6,17 \\
\end{array}$ \\
\hline \multicolumn{3}{|c|}{ INTV. INFERIOR $=110,3 \mathrm{~m}-\mathrm{PF}$} & \multicolumn{3}{|c|}{ INTV. INFERIOR $=80,3 \mathrm{~m}-\mathrm{PF}$} \\
\hline $\begin{array}{l}\text { Máximo } \\
\text { Mínimo } \\
\text { Média } \\
\text { Mediana }\end{array}$ & $\begin{array}{c}\text { DIR } \\
58,44 \\
4,78 \\
11,04 \\
8,31\end{array}$ & $\begin{array}{c}\text { GR } \\
43,00 \\
6,00 \\
10,27 \\
8,24\end{array}$ & $\begin{array}{l}\text { Máximo } \\
\text { Mínimo } \\
\text { Média } \\
\text { Mediana }\end{array}$ & $\begin{array}{c}\text { DIR } \\
20.336,04 \\
4,48 \\
87,42 \\
10,82\end{array}$ & $\begin{array}{c}\mathrm{SN} \\
32,65 \\
5,52 \\
12,81 \\
9,77\end{array}$ \\
\hline
\end{tabular}


Estes exemplos podem ser considerados bem mais significativos que o de STOTT; SMITH (1974.), porquanto foram obtidos em poços distintos, perfurados por empresas também distintas e separados por distâncias que inviabilizam a interferência dos filtrados entre eles. O poço 1 dista $3 \mathrm{~km}$ do poço 2 e o poço 3 está a 1,5 km do poço 4 .

\section{CONCLUSÃO}

Este trabalho analisou apenas o comportamento elétrico de um total de 355 fluidos de perfuração sobre as curvas Normal Curta (RSN ou R16) e a Indução 6FF40 (DIR) e não o hidráulico ou hidrodinâmico.

Durante a perfuração, o fluido deve ser freqüentemente monitorado em suas características filtrantes para que não venha produzir rebocos (ou filmes) espessos e/ou grandes diâmetros de invasão. Quanto mais espesso o reboco, maior a quantidade de filtrado fornecida para as camadas e, por conseqüência, maior a espessura radial da zona lavada/invadida. Ocorrendo grandes invasões, as curvas de diferentes profundidades de investigação registrarão valores diferentes, a não ser em camadas impermeáveis ou quando $\mathrm{Rmf}=\mathrm{Rw}$.

Como não foram encontradas evidências, nos dados analisados, de características elétricas capazes de modificar sensivelmente o comportamento dos filtrados, quer dos fluidos com bentonita, quer com polímeros naturais modificados e/ou sintéticos, acredita-se que quaisquer diferenças entre a RSN e a DIR devam ser creditadas a fatores outros, tais como a presença de uma maior ou menor invasão radial do filtrado (Di) e ao princípio físico de medição (elétrico ou indutivo) dessas curvas.

No entender dos autores, com base nos resultados obtidos, as diferenças de resistividades têm origem nas diferenças entre as profundidades de invasão dos fluidos de perfuração com bentonita ou polímero. Os fluidos bentoníticos invadem mais profundamente que os poliméricos, daí as leituras consistentemente, mais baixas das resistividades SN e DIR (pela maior influência da zona lavada/invadida) dos furos perfurados com bentonita, fatos estes que podem vir a produzir cálculos incorretos de Rw e SDT.

$\mathrm{O}$ ideal, portanto, seria que durante a perfuração dos poços para água, houvesse um rigoroso controle da perda de água dos fluidos de perfuração, visando não somente a estabilização dos furos e demais propriedades reológicas, mas principalmente a minimização dos diâmetros de invasão, dando preferência aos fluidos poliméricos. Aliado a tal precaução evitar usar, dadas as situações adversas apontadas, as curvas elétricas convencionais (RSN, RLN e RLAT) nos cálculos quantitativos porquanto elas deixam de representar a realidade, trocando-as por curvas de caráter eletromagnético (Indução 6FF40), não distorsivas em fluidos pouco condutivos, como os são na pesquisa da água subterrânea.

Os perfis geofísicos, na dependência dos conhecimentos da geologia da área e dos princípios físicos de cada curva usada, são os registros mais confiáveis para a identificação dos potenciais aqüíferos, indicando o correto posicionamento dos filtros. $\mathrm{O}$ custo inicial aparentemente alto de uma perfilagem geofísica e o conseqüente prolongamento da vida útil do poço podem ser traduzidos pelo menor custo final do metro cúbico da água produzida.

\section{AGRADECIMENTOS}

Os autores expressam seus melhores agradecimentos ao diretor da SYSTEM MUD, Dr. Eugênio Pereira, pela leitura crítica e sugestões relativas aos fluidos de perfuração.

\section{REFERÊNCIAS}

ALGER, R. P.; HARRISON, C. W. Improved fresh water assessement in sand aquifers utilizing geophysical well logs, In: The Log Analyst, 30(1), 31-44, 1989

ARCHIE, G.A. The electrical resistivity log as an aid in determining some reservoir characteristics, Journal of Petroleum Tecnology, jan, TP 1422, 1942.

CLAVIER, C.; COATES, G.; DUMANOIR, J. Theoretical and experimental bases for the dual water model for the interpretation of shaly sands, In: Soc. Pet. Eng. Jour., 4, pp 153-168, 1984
GIRÃO NERY, G. Estudo da eficiência na filtração osmótica da bentonita e folhelhos triturados da formação Candeias, bacia do Recôncavo, Bahia, Brasil, 1989, dissertação de mestrado - UFBA.

GIRÃO NERY, G. Equações hiperbólicas relacionando Rw com SDT: Determinação da qualidade da água subterrânea através dos perfis geofísicos. In. Anais do Cong. Bras. de Água Subterrâneas, Salvador, 1994.

GIRÃO NERY, G. Perfilagem Geofísica Aplicada à Água Subterrânea, Capítulo 10, in: 
FEITOSA, F.A.C; MANOEL Fo., J. SCHLUMBERGER. Schlumberger Educational Hidrogeologia, Conceitos e Aplicações, CPRM, Services, Log Interpretation Charts e Principles / 2000 Applications, 1989

LIMA, O. A. L.; G. G. NERY; CLENNELL, M. B. Interpretation of resistivity log in fresh-water aquifers, In: Anais $7^{\text {th }}$ Intern. Cong. SBGf, TS 16, pp 1496-99, 1991.

LIMA, A. O. L.; DALCIN, C. L. R. Application of a new shaly sand model for interpretating resistivity and dielectric log measurements. In: The Log Analyst, 36(2), 29-41, 1995.

LIMA, A. O. L; CLENNELL, M. B.; GIRÁO

NERY, G; NIWAS, S. A volumetric approach for the resistivity response of fresh water shaly sandstone. Aprovada para publicação In: Geophysics, jan 2005.

PEREIRA, E. Fluidos de Perfuração: O Uso de Inibidores de Argila como Solução dos Problemas de Sondagem. In: Anais Encontro Nacional de Perfuradores de Poços, Recife, 2001

STOTT, G. A, SMITH, A. L. Organic Polymer Drilling Fluids, American Society of Agricultural Engineers, Winter Meeting, paper 74-2520., 1974

SYSTEMMUD. Química dos Polímeros - Parte III, divulgação na Internet, com direitos reservados systemmud.com.br/atualidade fluido_cia_01.htm ., 2001

WAXMAN. M. H.; SMITS, L. J. M. Electrical Condutivities in oil-bearing shaly sands. In: Soc. Pet. Eng. Jour., 243, pp 107-122, 1968

YAALON, D.H. Mineral composition of average shales. Clay mineralogy Bull., v.5: 31-36, 1962 